\title{
Artigo
}

\section{MILITÂNCIA CÊNICA NO TEATRO NEGRO BRASILEIRO}

\author{
SCENIC MILITANCY IN BRAZILIAN \\ BLACK THEATER
}

\author{
MILITANCIA ESCÉNICA EN EL TEATRO \\ NEGRO BRASILEÑO
}

\section{Régia Mabel da Silva Freitas}

\author{
Régia Mabel da Silva Freitas \\ Doutoranda do Programa Multidisciplinar e \\ Multi-Institucional em Difusão do Conhecimento, \\ na Universidade Federal da Bahia, sob orientação \\ da professora doutora Rosângela Costa Araújo. \\ Docente de Graduação e Pós-Graduação em \\ faculdades privadas e articuladora de arte e \\ cultura dos ensinos fundamental e médio \\ da rede pública do estado da Bahia. \\ Autora de Bando de Teatro Olodum (2014).
}




\section{Resumo}

Esta pesquisa investiga a militância cênica no teatro negro brasileiro. De natureza qualitativa, cunho etnográfico e percurso exploratóriodescritivo, os dados foram coletados com revisão bibliográfica e análise documental. O referencial teórico aporta-se em livros, revistas, produções acadêmicas, sites, blogs, vídeos, documentários entre outras fontes que abordam o teatro negro como elemento de resistência e difusor de questões da negritude. Percebeu-se que cotidianamente os atores sempre discutiram com denodo em seus espetáculos a luta pela cidadania plena dos negros em busca da garantia dos seus direitos civis, políticos e sociais. Destarte, considerou-se o teatro mais uma estratégia negra afro-brasileira de resistência.

Palavras-chave: Teatro negro, Militância cênica, Difusão de questões da negritude.

\section{Abstract}

This research inquires the scenic militancy in Brazilian black theater. Through a qualitative nature, an ethnographic type and a descriptive exploratory way, the data were collected based on bibliographic review and documentary analysis. The theoretical reference is supported by books, magazines, academic productions, sites, blogs, videos, documentaries among other sources that approach the black theater as a resistance element and a diffuser of blackness aspects. It was perceived everyday that the actors always discussed in their shows hard for resourcefulness full citizenship of blacks in pursuit of warranty of their civil, political and social rights. Therefore, it was considered the theater black afro-Brazilian resistance strategies.

Keywords: Black theater, Scenic militancy, Blackness aspects diffusion. 


\section{Resumen}

Este texto investiga la militancia escénica en el teatro negro brasileño. De naturaleza cualitativa, etnográfica, exploratoria y descriptiva, la recopilación de datos se hace por revisión de la literatura y análisis de documentos. El marco teórico se basa en libros, revistas, producciones académicas, sitios web, blogs, vídeos, documentales y otras fuentes que abordan el teatro negro como elemento de resistencia y como difusor de temas de la negritud. Se percibió que de manera cotidiana los actores siempre discutieron con denuedo en sus espectáculos la lucha por la ciudadanía plena de los negros en busca de la garantía de sus derechos civiles, políticos y sociales. Por lo tanto, se consideró el teatro más una estrategia negra afrobrasileña de resistencia.

Palabras clave: Teatro negro, Militancia escénica, Difusión de temas de la negritud.

\section{Subindo as cortinas}

O teatro é a arte que traz, etimologicamente, o verbo "olhar" como possibilidade de enxergar a outrem e a si. Num espaço geográfico organizado para um público ver, tacitamente de caráter formativo, oportuniza-se conhecer e refletir. Essa forma de expressão sociopolítica, que dialoga com outras linguagens artísticas, como as artes plásticas, a dança, a literatura, a música entre outras, é uma difusora cultural e política.

Desde João Cândido Ferreira (De Chocolat) com as Companhias Negra de Revistas (1926) e Teatral Ba-Ta-Clan Preta (1927) e, mais tarde, em 1944, Abdias do Nascimento com o Teatro Experimental do Negro (TEN), acoplou-se a palavra "negro" a essa arte teatral. Mais que uma mera decisão semântica, foi um posicionamento ideológico. Essa plêiade de artistas negros decidiu intensificar a crítica contra o preconceito e socializar politicamente experiências, memórias e valores culturais ainda não devidamente apresentados pelos discursos e palcos branco-ocidentais.

A expressão Teatro Negro, cunhada conscienciosamente pautando as suas concepções cênicas num projeto de mobilização política como mais uma estratégia de resistência, foi a insurgência de mais um movimento sociocultural 
negro. Mais do que apresentação de performances negras (bumba-meu-boi, congadas), ultrapassando a presença negra com personagens subalternizados e/ou arquetípicos (cômico, anedótico, feio), potencializa espetáculos declaradamente militantes (LIMA, 2011).

Essa postura assumidamente política do Teatro Negro, que se pauta nas questões da negritude (pré e pós-Abolição), ressemantiza o legado da ancestralidade, valoriza a cultura afro-brasileira e coaduna as vertentes artística e ideológica. Como protagonistas de suas próprias histórias, lutando pela conquista da cidadania plena, os artistas militam cotidianamente contra a discriminação racial através de um contradiscurso da hegemônica historiografia brasileira, do mito da democracia racial e da ideologia do branqueamento. Por esse embate,

além de lidar com as questões derivadas de sua condição política (afirmar seu discurso e combater o que o contradiz), ainda tem que justificar a necessidade de sua própria existência. Ora, é a sua própria existência, em condição de resistência, que justifica sua necessidade. Necessidade de preencher lacunas, tais como a ausência de atores, autores, textos e personagens negras, livres de estereótipos e da coisificação. (Ibid., p. 84)

A abertura de um espaço de militância cênica que utiliza o discurso político em prol da cidadania dos negros como mola-mestra é contínua nas mais distintas regiões brasileiras. Essas companhias teatrais são espaços multirreferenciais de aprendizagem em que as culturas negras se constituem com "interseções, inscrições e disjunções, fusões e transformações, confluências e desvios, rupturas e relações, divergências, multiplicidade, origens e disseminações" (MARTINS, 1997, p. 25).

O Grupo Bambarê - Arte e Cultura Negra, o Bando de Teatro Olodum, a Companhia Teatral Zumbi dos Palmares, Os Crespos e o Grupo Teatral Caixa Preta enegrecem palcos com sua arte político-ideológica, promovendo formação intelectual e dramática para a plateia e os artistas. Como traços norteadores dos seus respectivos discursos cênico-dramáticos, temos:

1. O contínuo exercício de uma memória cultural dialógica [...], entrelugar de cruzamentos culturais, filosóficos, metafísicos; 2. A utilização de estratégias que exprimem a teatralidade das manifestações culturais 
negras; [promove] um processo de desrealização e desconstrução do estereótipo; [e] procura questionar certas verdades universais. 3. A atualização de formas de expressão rituais negras, religiosas e seculares, como intertextos constitutivos do discurso teatral. 4. A reposição histórica da figuração do negro, movendo-o e deslocando-o da situação de objeto enunciado para a de sujeito produtor de discurso; 5 . A construção de imagens que desfiguram os emblemas da brancura, realçando traços da diferença negra. 6 . A elaboração de uma linguagem cênico-dramática que atraia e estimule a plateia. (MARTINS, 1995, p. 87-88, grifos nossos)

\section{Grupo Bambarê - Arte e Cultura Negra}

Em 25 de julho de 1986, em Belém, no Pará, ouviu-se um "bambarê" (em quimbundo, "muitas vozes") com o objetivo de superar o racismo e o preconceito impostos pela sociedade brasileira. Esse coro foi entoado por Edson Catendê, artistas negros paraenses, pernambucanos, baianos e maranhenses que criaram o Grupo Bambarê - Arte e Cultura Negra. Difundindo e fomentando expressões artísticas através de teatro, dança, música e performances, atores, autores e técnicos abordam questões das populações tradicionais de matriz africana.

Essa companhia participou de festivais de teatro em Belém e de eventos nacionais como os Fóruns Nacionais de Performance Negra, organizados pelo Bando de Teatro Olodum (e a Companhia Comuns, em Salvador, na Bahia). Ela também colabora com ações da Coordenadoria de Educação para a Promoção e Igualdade Racial local, divulgando e refletindo sobre as propostas do ensino da cultura afro-brasileira nas escolas.

Além disso, a companhia desenvolve atividades com o intuito de incluir socialmente a população negra e afro-religiosa e divulgar o candomblé como religião e resistência cultural, promove projetos como o Patùwá, com oficinas de teatro, poesia, dança e música para levar essas manifestações a comunidades distintas. Além disso, organiza e participa da Rádio Exu - comunicação comunitária de matriz africana, um

projeto de mídia étnica e racial que difunde os valores civilizatórios da matriz africana na diáspora brasileira e prima pelo combate ao racismo e pelo fortalecimento de redes solidárias de lutas sociais e das culturas 
negras com protagonismo negro, de povo tradicional de matriz africana (terreiro) e de juventude de terreiro. (RÁDIO EXU, 2016)

O Bambarê faz parte da Associação dos Filhos e Amigos do lle lya Omi Ase Ofá Kare ${ }^{1}$ (Afaia), também criada por Catendê, uma referência na área metropolitana de Belém, apartidária, sem fins lucrativos e ligada ao movimento negro. Face Negra Face - a história que não foi contada (1986), Negritude (1987), Èmí - a concepção yorubana do universo (1990), Ébano (1994), Griot e os Espíritos da Terra - da Era Cantida aos Dias Atuais (2011) são algumas das suas montagens.

Esse teatro afro-paraense leva ao palco a beleza da negritude brasileira, baseando-se nos saberes e músicas ritualísticas e populares, danças tribais, contos, poemas etc. Para a atriz Janaína Andrade (ESPETÁCULO..., 2016), "o teatro é uma das ferramentas da militância negra, [...] ferramenta primordial para estabelecer o diálogo. O teatro político, o teatro do oprimido, é a construção do corpo político em cena".

\section{Bando de Teatro Olodum}

Em 17 de outubro de 1990, Marcio Meirelles (direção), Chica Carelli (codireção e preparação musical), Maria Eugênia Milet (improvisação), Leda Ornelas (preparação corporal) e Hebe Alves (preparação vocal) criaram um grupo teatral de presença, estética e público-alvo populares. Ele apresentou uma proposta de linguagem cênica para tratar a realidade baiana ao presidente do Grupo Cultural Olodum João Jorge Rodrigues, que aceitou e firmou uma parceria com autonomia financeira e temática. Surgiu, assim, um bando de atores negros que, pelo viés do teatro, reiterava o rufar já intenso de protesto percussivo dos tambores do olodum (Bando de Teatro Olodum)2.

Após perder o apoio institucional do olodum, em 1994, por dissensão ideológica, o Bando manteve-se homônimo e deixou de ter em cena a Banda Mirim do Olodum, que se apresentava nos espetáculos; neste momento, os

1. O blog desta associação está disponível em: <https://goo.gl/koTfXa>. Acesso em: 30 dez. 2016.

2. O blog deste grupo está disponível em: <https://goo.gl/HqBdCu>. Acesso em: 3 jun. 2015. 
atores passaram a revelar e intensificar seu próprio talento percussivo. Ainda na década de 1990, saíram Milet, Ornelas e Alves e ingressaram no grupo o coreógrafo Zebrinha (José Carlos Arandiba, 1993) e o diretor musical Jarbas Bittencourt (1996). Esse teatro afro-baiano

trouxe à cena baiana memórias da África e dos seus signos de pertencimento e deu voz e vez ao movimento social negro na contemporaneidade. Encenando temáticas político-sociais e também refletindo sobre questões contemporâneas e locais, o Bando - grupo residente do Teatro Vila Velha desde 1994 - utiliza o palco como estratégia de resistência em seus espetáculos artístico-militantes. (FREITAS, 2014, p. 209)

Através da presença e temática negra até então quase inexistente nos palcos soteropolitanos, a reflexão sobre questões político-ideológicas em seus aportes estéticos e temáticos, a produção colaborativa dos partícipes, a pesquisa de campo para elaborar espetáculos e promover debates, fóruns, laboratórios, oficinas, palestras, seminários para robustecer o capital cultural, essa companhia promove um exímio teatro negro.

Seu repertório artístico inclui Essa é nossa praia (1991), Onovomundo (1991), Ó Paí, Ó! (1992), Woyseck (1992), Medeamaterial (1993), Bai Bai Pelô (1994), Zumbi (1995), Zumbi está vivo e continua lutando (1995), Erê pra toda vida - Xirê (1996), Ópera de três mirreis (1996), Cabaré da Rrrrraça (1997), Um tal de Dom Quixote (1998), Ópera de três reais (1998), Sonho de uma noite de verão (1999), Já fui (1999), Material Fatzer (2001), Relato de uma guerra que (não) acabou (2002), Oxente, cordel de novo? (2003), O muro (2004), Autorretrato aos 40 (2004), Áfricas (2006), Bença (2010), Dô (2012), Erê (2015), entre outros.

O Bando também promove projetos como Outras Áfricas (oficinas de teatro em escolas públicas), Respeito aos mais velhos (oficinas de memória, identidade, dança e música em cidades das pesquisas de campo) e Tomaladacá (abertura de espaço para artistas de escolas públicas, igreja e teatro de bairro), organiza festivais (A cena tá preta!) para visibilizar a arte negra local, coordena oficinas de performance negra (formação teórico-artística para jovens) e, com a Companhia dos Comuns, realizou três edições (2005, 2006 e 2009) do Fórum Nacional de Performance Negra (promoção de palestras, mesas redondas, debates, oficinas e grupos de trabalho). 
São outras atividades do grupo: Essa é nossa praia, na Televisão Educativa (Bahia); participações no clipe internacional "Samba Reggae", de Jimmy Cliff (1991), no clipe "Jesus Cristo", de Mara Maravilha (1993), nos filmes Jenipapo, de Monique Gardenberg (1994) e Jardim das folhas sagradas, de Póla Ribeiro (2011); publicação da Trilogia do pelô (livro composto por Essa é nossa praia, Ó Paí, Ó! e Bai Bai Pelô, além de outros textos) em 1995; a adaptação homônima do espetáculo Ó Paí, Ó! para o cinema (2007) e para a minissérie da Rede Globo (2008 e 2009).

\section{Companhia Teatral Zumbi dos Palmares}

Em 20 de novembro de 1695 morreu o herói negro Zumbi dos Palmares, em 20 de novembro de 1996 morreu o ator, considerado o anjo negro da Bahia, Mário Gusmão e, em 20 de novembro de 2004, nasceu mais um grupo teatral negro almejando militar cenicamente: a Companhia Teatral Zumbi dos Palmares, em Goiânia. Paulo Vitória, Maria Rosalina Paula, Marli Silva, Uander Silva e Israel Neto não poderiam escolher uma data mais significativa (Dia da Consciência Negra, instituída desde 2003 pela Lei no $10.639 / 2003^{3}$ ) para fundar um coletivo que também prima debates e reflexões sobre questões raciais (COMPANHIA TEATRAL ZUMBI DOS PALMARES, 2013).

A história de luta pelo viés artístico da Zumbi confunde-se com a própria trajetória do movimento negro local. O seu intuito é promover a

a) valorização dos artistas negros e das artistas negras do estado de Goiás; b) Realização de atividades de inclusão social; c) Conscientização sobre a importância da Educação, Cidadania, Direitos Humanos e Meio Ambiente, rumo à igualdade racial d) Realização de espetáculos, cenas curtas, estudos teatrais, oficinas teatrais, baseado em vários teatrólogos, dentre eles Abdias do Nascimento. (COMPANHIA TEATRAL ZUMBI DOS PALMARES, 2013)

O nome do grupo foi resultado da participação de Vitória no I Fórum Nacional de Performance Negra. Esse evento, além de instrumentalizá-lo conceitualmente, estimulou a realizar o I Fórum de Arte e Cultura Negra

3. O texto completo desta lei está na homepage do Planalto. Disponível em: <https://goo.gl/ cMua9C>. Acesso em: 23 jun. 2017. 
do estado de Goiás. Integrante do Fórum Étnico-Racial de Educação, do Observatório Social, do Fórum Nacional Ensino Religioso, do curso de capacitação para implementar a Lei oㅜ 10.639, junto ao Ministério da Educação, em Mato Grosso do Sul, e do Comitê Estadual de Direitos Humanos, a Zumbi faz esquetes, produz textos artísticos, promove oficinas teatrais nos encontros Afro-Goianos, entre outros.

A companhia, além de participar do Fórum de Educação da Diversidade Étnico-racial do Estado de Goiás, Encontro de Gestores da Questão ÉtnicoRacial, Conferência Nacional dos Direitos Humanos, engaja-se também em outras frentes, participando do Conselho Estadual da Mulher, do Conselho de Segurança Alimentar do Estado de Goiás, do Fórum Goiano de Combate aos Agrotóxicos, da luta Contra a Homofobia. Dentre os espetáculos apresentados, temos Senhora liberdade, Anjo Abdias e Um novo olhar negro.

\section{Os Crespos}

Em 13 de maio de 1888 foi assinada a Lei Áurea. Longe de ser uma dádiva da princesa bondosa num gesto caritativo, essa rubrica deu respaldo jurídico de libertação aos legítimos sujeitos históricos responsáveis pelo seu processo de emancipação: os negros. Em 13 de maio de 2005, na Escola de Arte Dramática da Universidade de São Paulo, iniciou-se mais um processo de autonomia também protagonizado por negros, com a criação do grupo de estudos Negros em Questão, formado por atores-pesquisadores como Gal Quaresma, Lucélia Sergio e outros.

Esses jovens universitários negros desejavam "discutir a sua formação e como foco estudar a história do negro nas artes cênicas e nos multimeios no Brasil, numa instituição em que esta discussão não existia." (GRUPO..., 2009). Para tal, promoveram eventos, como o Encontro Pensando a Negritude, com mostra de curtas-metragens do cineasta Jéferson De (Narciso do Rap, Carolina, e Distraída pra Morte), exposição permanente Traços e Relatos e também mesas-redondas com atores, diretores, dramaturgos, docentes e discentes.

Além disso, com o intuito de verticalizar seus conhecimentos, participou da II e III edições do Fórum Nacional de Performance Negra. Esse núcleo de estudos resolveu criar a Companhia Filhos de Olorum, que depois passou a 
se chamar Os Crespos. Partindo também da experiência do TEN, esse grupo teatral de pesquisa cênica e audiovisual, composto de atores negros, promove debates e intervenções públicas para formar plateia e construir um discurso poético que debata a sociabilidade do indivíduo negro na sociedade contemporânea e seus desdobramentos históricos.

A ininterrupta pesquisa para fundamentação teórica de seus espetáculos, mistura de linguagens (vídeo, música, fotografia, instalação etc.) para facilitar a compreensão da plateia e a busca por desfazer estereótipos da identidade negra e rever nosso lugar na sociedade delatam com veemência a militância cênica do grupo. Como instrumento político, os textos dramáticos trazem em seu bojo a crítica social no combate a injustiças raciais, sexuais, de gênero e outras.

Dentre as montagens, encontram-se Ensaio sobre Carolina (2007), Anjo Negro + A missão (2008), A construção da imagem e a imagem construída (2009). Como parte do projeto de pesquisa sobre racismo na história do Brasil e seus desdobramentos na contemporaneidade, fez também quatro curtas: Desculpa, D.O.R., Imagem e Autoimagem, e Nego Tudo. Os espetáculos Além do ponto (2011), Engravidei, pari cavalos e aprendi a voar sem asas (2013), Cartas a Madame Satã - ou me desespero sem notícias suas (2014) formam a trilogia Dos desmanches aos sonhos.

O projeto De Brasa e Pólvora - Zonas Incendiárias, Panfletos Poéticos trouxe espetáculos que revisitam a historiografia sobre o potencial insurrecional negro (Ninhos e revides - mirando o Haiti, Alguma coisa a ver com uma missão, e continuará em Revolta das vassouras - garis, domésticas, coveiros e outros fodidos). Dentre os eventos estão I e II Mostra Reflexiva de Cinema Faz lá o Café, Reflexiva de Filmes, I Mostra de Teatro Negro de São Paulo e a publicação da revista Legítima Defesa - uma revista de teatro negro.

\section{Grupo teatral Caixa Preta}

Em 2002, em Porto Alegre, no Rio Grande do Sul, Jessé Oliveira, Vera Lopes, Marcelo de Paula e Márcio Oliveira criaram mais uma companhia teatral com o intuito de resgatar e aprofundar a proposta do TEN com realização e identificação negras: o Grupo Teatral Caixa Preta. Assim como o sistema de registro dos aviões, essa Caixa Preta tem o intuito de (re)lembrar o potencial 
da arte negra, enaltecer a cultura afro-brasileira e reconhecer a história do negro, representando-o em suas diferentes dimensões.

Desejando ampliar o restrito espaço dos artistas, diretores e técnicos negros e primando por sua formação técnica, intelectual e criativa, esse grupo, que se considera um polo catalizador de ações no campo da cultura negra contemporânea, através de um notável engajamento político-cultural, desvela sua militância cênica com o escopo de

instrumentalizar atores negros na sua formação técnica em estilos de representação, habilidades corporais e teóricas, uma vez que, em sua maioria, seus integrantes possuem uma formação puramente empírica e descontinuada, muitas vezes baseadas em modelos dramáticos tradicionais, principalmente no realismo-naturalismo e em fórmulas advindas de modelos associados ao audiovisual. Também se propõe a trabalhar as questões pertinentes à formação ideológica, elemento imprescindível à atuação integral do ator como artista e cidadão sem, entretanto, perder de vista que o objetivo é fazer arte, uma arte engajada e qualificada em seus propósitos. (GRUPO..., [201?])

Transegun (2003), Hamlet sincrético (2005), Madrugada, me proteja (2006), Antígona BR (2008), O osso de Mor Lam (2009), Dois nós na noite (2010) e Ori Oresteia (2014) são algumas de suas montagens. Esse coletivo também edita a Revista Matriz, periódico que se dedica à arte negra brasileira e latino-americana como mais um instrumento de reflexão e debate, realizando seis edições do Encontro de Arte de Matriz Africana com o intuito de alargar as fronteiras e estabelecer salutares interações entre grupos artísticos, reverenciando a diversidade cultural brasileira.

\section{Descendo as cortinas}

$\mathrm{Na}$ apresentação de seus espetáculos político-filosóficos, pesquisas de autores e dramaturgos negros, elaboração de textos dramáticos, cruzamento cultural através de estudos comparativos entre mitologias, organização de eventos (encontros, fóruns, mesas-redondas e seminários), promoção de cursos e oficinas, produção de revistas, parceria com órgãos locais e intercâmbios para formação artístico-teórica, o Bambarê, a Zumbi, o Bando, Os Crespos e o Caixa Preta militam cenicamente. 
"O prazer de ser negro manifesta-se, no palco, pelo desejo de mostrar-se negro, exibindo-se o corpo como fala, enunciação". Essa relação decolonial apresenta nos palcos um contradiscurso da vigente narrativa secular de anomia social e incapacidade intelectiva negra, opõe-se aos "efeitos corrosivos do racismo na constituição do sujeito" e almeja mudar a situação do negro no Brasil "pela releitura do corpo, pela reversão da história, pela revitalização da memória, pela vontade política de promover mudanças" (MARTINS, 1995, p. 144-146).

Esses artistas negros, com posicionamento crítico, ressemantizam o legado ancestral e delatam, aliado ao seu caráter artístico, sua veia político-social. Essas manifestações artísticas se pautam nos repertórios histórico-culturais de seus intérpretes, que reelaboram a múltipla e diversa tradição africana e transcendem os entraves impostos pelo preconceito branco-ocidental.

\section{Referências bibliográficas}

COMPANHIA TEATRAL ZUMBI DOS PALMARES. Histórico: Cia Teatral Zumbi dos Palmares. 2013. Disponível em: <https://goo.gl/hoU2eJ>. Acesso em: 13 jan. 2017. ESPETÁCULO premiado fala sobre a história dos negros no Brasil. G1, Belém, 12 nov. 2016. Disponível em: <https://goo.gl/WthPHk>. Acesso em: 30 dez. 2016. FREITAS, R. M. Bando de Teatro Olodum: uma política social in cena. Recife: UFPE, 2014.

GRUPO caixa preta: histórico. Ocupação Cênica Hospital Psiquiátrico São Pedro.

[S.I.]: [201-?]. Disponível em: <https://goo.gl/69ZF6r>. Acesso em: 20 jun. 2017. GRUPO teatral companhia os crespos: histórico do grupo. Negro é Arte, Salvador, 15 ago. 2009. Disponível em: <https://goo.gl/RfWZWi>. Acesso em: 31 jan. 2017. LIMA, E. T. Teatro negro, existência por resistência: problemáticas de um teatro brasileiro. Repertório, Salvador, n. 17, p. 82-88, 2011.

MARTINS, L. M. A cena em sombras. São Paulo: Perspectiva, 1995.

Afrografias da memória. São Paulo: Perspectiva, 1997.

RÁDIO EXU. Funcionamento da Rádio Exu: o projeto. [201-?]. Disponível em: <https://goo.gl/RhjA8k>. Acesso em: 30 dez. 2016.

Recebido em 13/04/2017

Aprovado em 06/06/2017

Publicado em 05/09/2017 